\title{
Fibroblast growth factor-21 enhances mitochondrial functions and increases the activity of PGC-1a in human dopaminergic neurons via Sirtuin-1
}

\author{
Johanna Mäkelä ${ }^{1,2}$, Timofey V Tselykh ${ }^{1,2}$, Francesca Maiorana ${ }^{1,3}$, Ove Eriksson ${ }^{1}$, Hai Thi Do ${ }^{1,2}$, Giuseppa Mudò ${ }^{3}$,
} Laura T Korhonen ${ }^{1,2}$, Natale Belluardo ${ }^{3}$ and Dan Lindholm ${ }^{1,2^{*}}$

\begin{abstract}
Mitochondrial dysfunctions accompany several neurodegenerative disorders and contribute to disease pathogenesis among others in Parkinson's disease (PD). Peroxisome proliferator-activated receptor $\gamma$ coactivator-1a (PGC-1a) is a major regulator of mitochondrial functions and biogenesis, and was suggested as a therapeutic target in PD. PGC-1a is regulated by both transcriptional and posttranslational events involving also the action of growth factors. Fibroblast growth factor-21 (FGF21) is a regulator of glucose and fatty acid metabolism in the body but little is known about its action in the brain. We show here that FGF21 increased the levels and activity of PGC-1a and elevated mitochondrial antioxidants in human dopaminergic cells in culture. The activation of PGC-1a by FGF21 occurred via the $\mathrm{NAD}^{+}$-dependent deacetylase Sirtuin-1 (SIRT1) subsequent to an increase in the enzyme, nicotinamide phosphoribosyltransferase (Nampt). FGF21 also enhanced mitochondrial respiratory capacity in human dopaminergic neurons as shown in real-time analyses of living cells. FGF21 is present in the brain including midbrain and is expressed by glial cells in culture. These results show that FGF21 activates PGC-1a and increases mitochondrial efficacy in human dopaminergic neurons suggesting that FGF21 could potentially play a role in dopaminergic neuron viability and in PD.
\end{abstract}

Keywords: FGF21; PGC-1a; SIRT1; Dopaminergic neurons; Mitochondria; Parkinson's disease

\section{Introduction}

Parkinson's disease (PD) is characterized by degeneration of dopaminergic neurons in substantia nigra pars compacta by mechanisms that are not fully understood (Jenner and Olanow 2006; Gupta et al. 2008; Lees et al. 2009). Mitochondrial dysfunctions and changes in cell metabolism with an altered growth factor signaling are associated with the disease process in PD (Abou-Sleiman et al. 2006; Lin and Beal 2006; Banerjee et al. 2009). Mitochondria influence a number of cellular functions ranging from regulation of cell energy and metabolism, and the

\footnotetext{
* Correspondence: dan.lindholm@helsinki.fi

'Institute of Biomedicine/Biochemistry and Developmental Biology, University of Helsinki, Haartmaninkatu 8, FIN-00290 Helsinki, Finland ${ }^{2}$ Minerva Foundation Institute for Medical Research, Biomedicum-2, FIN-00290 Helsinki, Finland

Full list of author information is available at the end of the article
}

control of intracellular calcium and cell death pathways (Lindholm et al. 2004; Nunnari and Suomalainen 2012). Mitochondria are also the major source of reactive oxygen species (ROS) in the cell occurring as a consequence of oxidative phosphorylation. In neurodegenerative disease including PD increased levels of ROS are thought to contribute to neuronal loss (Henchcliffe and Beal 2008; Zhou et al. 2008).

Peroxisome proliferator activated receptor $\gamma$ coactivator $1 \alpha(\mathrm{PGC}-1 \alpha)$ is a transcriptional coactivator that is a master regulator of mitochondrial biogenesis and cell viability (Wu et al. 1999; Houten and Auwerx 2004; Lin et al. 2005). PGC-1 $\alpha$ is also involved in cell defense against oxidative stress by stimulating production of antioxidant enzymes in the cell (St-Pierre et al. 2006). PGC$1 \alpha$ has been studied mainly for its action in cell and lipid metabolism and in metabolic disease such as 
diabetes and obesity (Handschin and Spiegelman 2006; Kleiner et al. 2012). In the brain gene deletion of PGC$1 \alpha$ caused an increased susceptibility of neurons against excitotoxic injury (St-Pierre et al. 2006; Cui et al. 2006). A meta-analyses of PD patient samples indicated that PGC-1 $\alpha$ and its gene networks are potential therapeutic targets for early intervention in the disease (Zheng et al. 2010). Recent studies with overexpression of PGC-1 $\alpha$ in mouse brain showed that it exerts a protective effect on dopaminergic neurons in the 1-methyl-4-phenyl-1, 2, 3, 6-tetrahydropyridine (MPTP) mouse model of PD (Mudo et al. 2012).

Available data shows that PGC- $1 \alpha$ is regulated by both transcriptional and posttranscriptional mechanisms (Houten and Auwerx 2004; Lindholm et al. 2012). The deacetylase Sirtuin-1 (SIRT1) can activate PGC-1 $\alpha$ by means of protein deacetylation as shown in different cell types (Rodgers and Puigserver 2007; Nemoto et al. 2005). SIRT1 is a NAD ${ }^{+}$-dependent enzyme that plays a critical role in the regulation of metabolism and the cell response to nutrients and caloric restriction (Rodgers and Puigserver 2007; Revollo et al. 2004; Lagouge et al. 2006; Alcaín and Villalba 2009). Changes in SIRT1 has been linked to aging (Alcaín and Villalba 2009; Mercken et al. 2013) and to metabolic and neurodegenerative diseases (Mudo et al. 2012; Kim et al. 2007; Outeiro et al. 2008).

Fibroblast growth factor-21 (FGF21) a member of the fibroblast growth factor 19 subfamily together with FGF19 and FGF23 and is primarily expressed in the liver (Nishimura et al. 2000). FGF21 has an endocrine function in the body and plays a role in cell metabolism by stimulating glucose uptake (Kharitonenkov et al. 2005) by influencing fatty acid metabolism (Potthoff et al. 2009) and by controlling lipoprotein receptor (LDLR) levels and lipoprotein uptake in liver cells (Do et al. 2012). FGF21 was shown to increase PGC-1 $\alpha$ in liver and fat tissue (Potthoff et al. 2009; Fisher et al. 2012) and to regulate energy homeostasis in adipocytes via the SIRT1-PGC1 pathway (Chau et al. 2010). The expression and functions of FGF21 in brain cells are so far unknown.

In this work, we have studied the role of FGF21 in the regulation of PGC- $1 \alpha$ and mitochondria in human dopaminergic neurons. As a model we employed cultured human dopaminergic neurons derived from midbrain neuronal precursor cells obtained from human embryo (Lotharius et al. 2002). Results showed that FGF21 influences the levels and activity of PGC- $1 \alpha$ in the human dopaminergic neurons by increasing SIRT1 and nicotinamide adenine dinucleotide $\left(\mathrm{NAD}^{+}\right)$in the cells. The activation of PGC- $1 \alpha$ was followed by increased levels of the antioxidant enzymes, sodium dismutase 2 (SOD2) and thioredoxin 2 (Trx2) and by an enhanced mitochondrial respiratory capacity as revealed by real-time in living neurons.

\section{Materials and methods Cell culture}

Human mesencephalon neuronal precursor cells (MESC2.10 cells) were cultured in poly-D-lysine (Sigma, St Louis, MO, USA) coated flasks $\left(75 \mathrm{~cm}^{2}\right)$ in Dulbeccos modified Eagle medium (DMEM)/F12 medium (Gibco, Invitrogen, Calrsbad, CA, USA) supplemented with B27 (Gibco) and Penicillin/streptomycin and human basic FGF $20 \mathrm{ng} / \mathrm{ml}$ (Peprotech, Rocky Hill, NJ, USA). To induce neuronal differentiation, cells were cultured for 6 days on poly-Dlysine/laminin (Sigma) coated wells at a density of 30,000 cells $/ \mathrm{cm}^{2}$ in a medium containing $1 \mu \mathrm{g} / \mathrm{ml}$ tetracyclin (Sigma) (Lotharius et al. 2002; Di Liberto et al. 2012). Medium was changed every second day and cell differentiation was monitored by the expression of markers for dopaminergic neurons such as tyrosine hydroxylase and dopamine transporter. Human dopaminergic cells were treated with $50 \mathrm{ng} / \mathrm{ml} \mathrm{FGF21} \mathrm{and} \mathrm{analyzed} \mathrm{as} \mathrm{described}$ in the text. In some experiments $20 \mu \mathrm{M}$ nicotinamide (NAM) was used to the cells to inhibit SIRT1. Glial cultures from newborn rodent brains were prepared and cultured in $10 \%$ fetal calf serum in DMEM as described previously (Lindholm et al. 1992; Mäkelä et al. 2010). The human hepatocyte cell line (Huh7) was used as a positive control for FGF21 expression (Do et al. 2012).

\section{Immunoblotting}

Differentiated MESC2.10 cells were treated with $50 \mathrm{ng} /$ ml FGF21 (R\&D Systems, Minneapolis, MN, USA) for $24 \mathrm{~h}$ and cells were lysed in RIPA buffer containing $150 \mathrm{mM} \mathrm{NaCl}, 1 \% \mathrm{NP}-40,0,25 \%$ sodium deoxycholate, $50 \mathrm{mM}$ Tris- $\mathrm{HCl} \mathrm{pH} 7.4$, and $0,1 \%$ sodium dodecyl sulfate (SDS). Immunoblotting was done essentially as described (Mudo et al. 2012; Do et al. 2012; Korhonen et al. 2001; Sokka et al. 2007). In brief, $30 \mu \mathrm{g}$ of protein was run on SDS-PAGE and transferred to Hybond-C Extra nitrocellulose membrane (Amersham Biosciences, Buckinghamshire, UK). The membrane was blocked in $5 \%$ non-fat milk-Tris buffered saline (TBS) for $1 \mathrm{~h}$ and room temperature and primary antibodies were added overnight at $+4{ }^{\circ} \mathrm{C}$. The antibodies used were: anti-SIRT1 (diluted 1:1000; Cell Signaling Technology, Danvers, MA, USA), anti-PBEF/NAMPT (1:1000; Abcam, Cambridge, UK), anti-SOD2 (1:5000; AbFrontier, Seoul, Korea), anti-Trx2 (1:1000; AbFrontier), anti- PGC-1 $\alpha$ (1:5000; Calbiochem, San Diego, CA, USA), anti- cytochrome oxidase IV (COX IV, 1:2000; Abcam), anti-mitochondrial transcription factor A (TFAM, 1:1000; Abcam), antiFGF21 (1:3000; Novus Biologicals, Littleton, CO, USA) and anti- $\beta$-actin (1:5000; Sigma). The membranes were washed with TBS-5\% Tween20 buffer and appropriate horseradish peroxidase (HRP)-conjugated secondary antibodies (1:2500; Jackson ImmunoResearch, West Grove, PA, USA) were added for $1 \mathrm{~h}$ at room temperature. Super 
Signal West Pico chemiluminescent substrate (Thermo, Waltham, MA, USA) was used for visualization of the bands, and ImageJ software for their quantification.

Different brain regions of adult mouse were dissected under stereomicroscopy and frozen in cooled isopentane as described before (Mudo et al. 2012). Tissue pieces were homogenized in cold RIPA buffer containing also $10 \mu \mathrm{g} / \mathrm{ml}$ aprotinin, $10 \mu \mathrm{g} / \mathrm{ml}$ leupeptin, $0.1 \mathrm{mM}$ phenylmethylsulfonyl fluoride, $100 \mu \mathrm{M}$ sodium orthovanadate $\left(\mathrm{Na}_{3} \mathrm{VO}_{4}\right)$ and $1 \mathrm{mM}$ ethylenediaminetetraacetic acid (EDTA; Sigma-Aldrich, St. Louis, MO, USA). The homogenate was left on ice for $30 \mathrm{~min}$ and centrifuged at $10,000 \times \mathrm{g}$ for $15 \mathrm{~min}$ at $4^{\circ} \mathrm{C}$ to yield supernatant fractions that were stored at $-80^{\circ} \mathrm{C}$ until use. To obtain enough material, the two $\mathrm{SN}$ were pooled. 30-40 $\mu \mathrm{g}$ of protein was subjected to immunoblotting as above using primary antibodies anti-FGF21 (1:3000) and $\beta$-actin as control. The membrane was processed as above using secondary antibodies and visualisation of bands was made by enhanced chemiluminescence.

\section{Immunoprecipitation}

Experiments were done essentially as described (Mudo et al. 2012; Revollo et al. 2004) using lysates from human dopaminergic cells treated with $50 \mathrm{ng} / \mathrm{ml}$ FGF21 for $24 \mathrm{~h}$ alone or together with $10 \mathrm{mM}$ nicotinamide (NAM; Acros organics, Geel, Belgium). In brief, 1,5 $\mu \mathrm{g}$ of antiPGC- $1 \alpha$ antibody (Calbiochem) was added to $500 \mu \mathrm{g}$ of cell lysates overnight at $+4^{\circ} \mathrm{C}$ under constant rotation. $50 \mu \mathrm{l}$ of Protein G-agarose (Roche, Basel, Switzerland) was then added to the samples and incubated for $6 \mathrm{~h}$. Beads were washed three times with RIPA buffer and samples were run on $8 \%$ SDS-PAGE, followed by transfer and immunoblottings as described above using first antiacetylated lysine antibodies (1:1000; Cell signaling technology) and then anti-PGC- $1 \alpha$ antibodies. The quantifications of the bands were done using ImageJ software. The degree of acetylation of PGC- $1 \alpha$ is an index for the activity of this protein in the cell (Mudo et al. 2012; Rodgers and Puigserver 2007).

\section{Luciferase assay}

Cells were transfected with $0,5 \mu \mathrm{g}$ of the PGC- $1 \alpha$-luciferase reporter constructs or the control pGL3 promoter constructs together with $0,025 \mu \mathrm{g}$ Renilla pRL-TK plasmid using Fugene (Promega, Madison, WI, USA). Cells were incubated for 2 days in the differentiation medium and $50 \mathrm{ng} / \mathrm{ml} \mathrm{FGF21} \mathrm{was} \mathrm{added} \mathrm{for} \mathrm{an} \mathrm{additional}$ $24 \mathrm{~h}$. Luciferase activity was measured using the DualLuciferase reporter Assay (Promega) and a GLOMAX 20/ 20 luminometer (Promega) as described previously (Mudo et al. 2012; Kairisalo et al. 2009). The values were normalized to those of Renilla.

\section{Determination of $\mathrm{NAD}^{+} / \mathrm{NADH}$ levels}

To analyze $\mathrm{NAD}^{+} / \mathrm{NADH}$ level in cells the absorbance at $450 \mathrm{~nm}$ was measured using Multiscan MS Version 3.0 spectrophotometer following the assay kit as provided by the manufacturer (Abcam).

\section{Real-time analyses of mitochondrial respiratory capacity in human dopaminergic neurons}

Cells were plated on Seahorse 96well plate (Seahorse Bioscience, Boston, MA USA) and differentiated for 5 days followed by a $24 \mathrm{~h}$-stimulation with $50 \mathrm{ng} / \mathrm{ml}$ FGF21. Medium was changed to $\mathrm{HCO}_{3}$-free DMEM (Sigma) containing $10 \mathrm{mM}$ pyruvate, $1 \mathrm{mM}$ l-glutamine and $10 \mathrm{mM}$ glucose $1 \mathrm{~h}$ prior to analyses and keeping cells at $+37^{\circ} \mathrm{C}$ without $\mathrm{CO}_{2}$. Oxygen consumption rate (OCR) in dopaminergic neurons was determined in real-time using theSeahorse XFe96 analyzer (Seahorse Bioscience) by determining oxygen consumption as response to the addition of various chemicals. Three 3 min cycles were run for every measurement and the Mitostress kit (Seahorse) was used containing the following compounds: $1 \mu \mathrm{M}$ Oligomycin (ATP synthase inhibitor), 0,8 $\mu \mathrm{M}$ Carbonyl cyanide 4-(trifluoromethoxy)phenylhydrazone (FCCP) (mitochondrial uncoupler), $1 \mu \mathrm{M}$ Rotenone (complex I inhibitor of the respiratory chain) and Antimycin A (complex III inhibitor).

\section{Mitochondrial DNA copy number}

DNA was isolated from human dopaminergic neurons using QIAamp DNA Mini Kit (QIAGEN, Hilden, Germany) according to manufacturer's protocol. The relative mitochondrial DNA (mtDNA) copy number was measured using quantitative PCR and comparing the ratio of mtDNA to nuclear DNA and the method described previously (Xie et al. 2013). In brief, the mitochondrially encoded $N A D H$ dehydrogenase 1 (ND1 gene) was used for quantifying mtDNA and human globulin (HGB) gene for nuclear DNA. The primer sequences used were: forward primer ND1-F: 5'-CCT AAA ACC CGC CAC ATC T-3', reverse primer ND1-R: 5'-GAG CGA TGG TGA GAG CTA AGG T-3'; forward primer HGB-F: 5'-GTG CAC CTG ACT CCT GAG GAG A-3', and reverse primer HGB-R: 5'-CCT TGA TAC CAA CCT GCC CAG-3'. The PCR reaction mixture contained $5 \mathrm{ng}$ DNA and $200 \mathrm{nmol} / \mathrm{l}$ of forward and reverse primers in $1 \mathrm{X}$ SYBR Green Mastermix (Roche). The reaction was carried out at $95^{\circ} \mathrm{C}$ for $10 \mathrm{~min}$ followed by at $95^{\circ} \mathrm{C}$ for $15 \mathrm{~s}$ and $60^{\circ} \mathrm{C}$ for $1 \mathrm{~min}$ using 40 cycles. Each sample was run in triplicates on a 96-well plate and water was used as negative control. QuantitativePCR (qPCR) amplification was performed using Light Cycler 480 II instrument (Roche) as described (Do et al. 2012; Hyrskyluoto et al. 2013). The ratio of mtDNA to nuclear DNA reflects the concentration of mtDNA per dopaminergic cell. 


\section{Electron microscopy and mitochondrial density analysis} Human dopaminergic neurons were stimulated with $50 \mathrm{ng} / \mathrm{ml} \mathrm{FGF21} \mathrm{for} 24 \mathrm{~h}$, fixed with 2,5\% glutaraldehyde in PBS for $1 \mathrm{~h}$ at room temperature, and washed two times for $1 \mathrm{~h}$ with $\mathrm{H}_{2} \mathrm{O}$. Postfixation was done using $1 \%$ osmiumtetroxide. The embedding and sectioning procedures were done essentially as described before (Korhonen et al. 2008). The sections were stained with lead citrate and uranyl acetate and viewed using a Jeol JEM-1400 transmission electron microscope (Jeol Ltd., Tokyo, Japan) equipped with Gatan Orius SC 1000B bottom mounted CCD-camera (Gatan Inc., USA). Mitochondria identified in the EM pictures of the cells were marked manually and the relative surface area was calculated using the ImageJ software. Results were pooled from different sections of control and FGF21-treated cells and the density of mitochondria was compared.

\section{Quantification and statistics}

Immunoblots were quantified with Image J quantification software. Results are expressed as percentage of controls and statistical analyses were performed using one-way analysis of variance (ANOVA) and Bonferroni's multiple comparison tests. Values are given as means \pm SD and $\mathrm{p}<0.05$ was considered as statistically significant.

\section{Results}

FGF21 increases levels and deacetylation of PGC-1a in cultured human dopaminergic neurons

In this work we used midbrain progenitor (MESC2.10) cells from human embryonic brain (Lotharius et al. 2002) that were further differentiated into dopaminergic neurons in culture (Figure 1A). Treatment of the

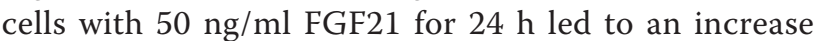
in PGC-1 $\alpha$ as shown by immunoblotting (Figure 1B). To clarify whether this involved increased gene expression we used the $P G C$ - $1 \alpha$-promoter linked to a luciferase reporter gene. Data showed that the gene activity of the PGC-1 $\alpha$ promoter was increased by FGF21 with no changes in the activity of the pGL3 basic-promoter used as control (Figure 1C). There was also an increase in PGC- $1 \alpha$ mRNA levels in FGF21treated dopaminergic neurons using quantitative PCR (data not shown). To study whether FGF21 may activate PGC- $1 \alpha$ we performed immunoprecipitation experiments followed by immunoblotting using antiPGC- $1 \alpha$ and anti-acetylated lysine antibodies. Data obtained showed that the relative degree of acetylation of PGC-1 $\alpha$ decreased in cells treated with FGF21 as compared to control (Figure 1D). Collectively these data indicate that FGF21 can increase both the level and the activation status of PGC-1 $\alpha$ in the human dopaminergic neurons.
FGF21 increases Nampt and NAD ${ }^{+}$levels and SIRT1 in the dopaminergic neurons

PGC- $1 \alpha$ can be post-transcriptionally modified in cells that affect its properties as gene coactivator (Houten and Auwerx 2004; Lin et al. 2005). SIRT1 is known to deacetylate PGC- $1 \alpha$ increasing its activity (Rodgers and Puigserver 2007). We were therefore interested to study possible effects of FGF21 on SIRT1 in the human dopaminergic neurons. Data showed that stimulation of cells for $24 \mathrm{~h}$ with $50 \mathrm{ng} / \mathrm{ml} \mathrm{FGF21} \mathrm{increased} \mathrm{the} \mathrm{levels} \mathrm{of}$ SIRT1 as analyzed by western blot (Figure 2A). We also observed that FGF21 treatment increased the levels of Nampt, which is the rate-limiting enzyme in $\mathrm{NAD}^{+}$biosynthesis (Figure 2B). FGF21 also increased the $\mathrm{NAD}^{+}$ levels in the dopaminergic neurons as shown using the $\mathrm{NAD}^{+} / \mathrm{NADH}$ assay (Figure $2 \mathrm{C}$ ). This shows that FGF21 increases Nampt and the $\mathrm{NAD}^{+}$levels in the dopaminergic neurons that subsequently activate SIRT1 and PGC-1 $\alpha$ in these cells. To substantiate this further, we incubated the neurons in the presence of the SIRT1inhibitor NAM that increased the degree of acetylation of PGC- $1 \alpha$ in the cells (Figure 2D). NAM also counteracted the deacetylation of PGC-1 $\alpha$ induced by FGF21 in these neurons (Figure 2D). Collectively these results show that FGF21 influences the Nampt/SIRT1 pathway in the human dopaminergic neurons leading to the activation of PGC-1 $\alpha$.

\section{FGF21 increases mitochondrial antioxidants in human dopaminergic neurons}

We have previously shown that overexpression of PGC$1 \alpha$ in transgenic mice led to an increase in the levels of SOD2 and Trx2, two mitochondrial antioxidants, in the substantia nigra harboring the dopaminergic neurons (Mudo et al. 2012). We therefore studied whether these antioxidants were also increased in human dopaminergic neurons after FGF21 treatments. Data showed that SOD2 and Trx2 were both significantly upregulated by FGF21 in these neurons (Figure 3A-C). This suggests that FGF21 via activation of PGC- $1 \alpha$ can increase these mitochondrial antioxidants that may contribute to neuroprotection against oxidative stress.

\section{FGF21 stimulates mitochondrial respiratory capacity of human dopaminergic neurons}

To study the effect of FGF21 on mitochondrial functions in dopaminergic neurons further we analyzed the cells in real-time using the Seahorse equipment as described in Methods. Data showed that the human dopaminergic neurons stimulated with FGF21 had an increased basal respiration and a higher maximal respiratory capacity as compared to control cells (Figure 4A-B). This result together with data on the antioxidants indicates that FGF21 is able to increase the mitochondrial efficacy and 

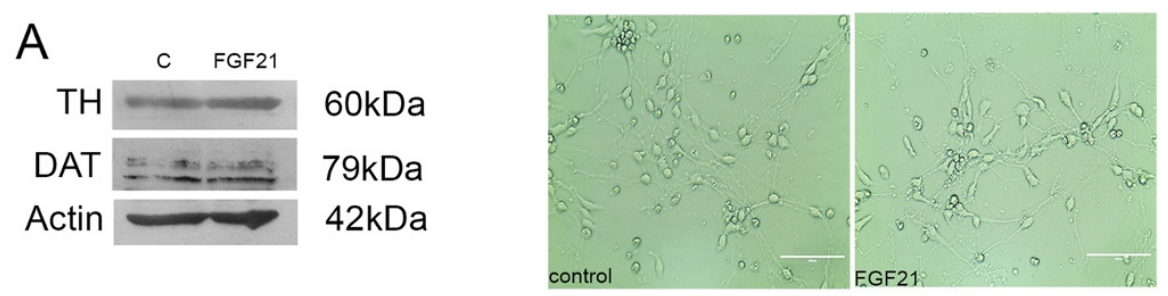

B

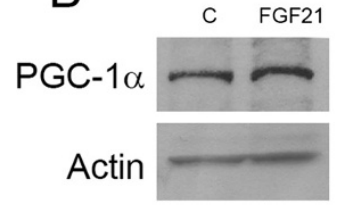

$100 \mathrm{kDa}$

$42 \mathrm{kDa}$

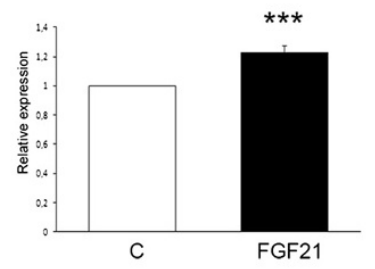

C
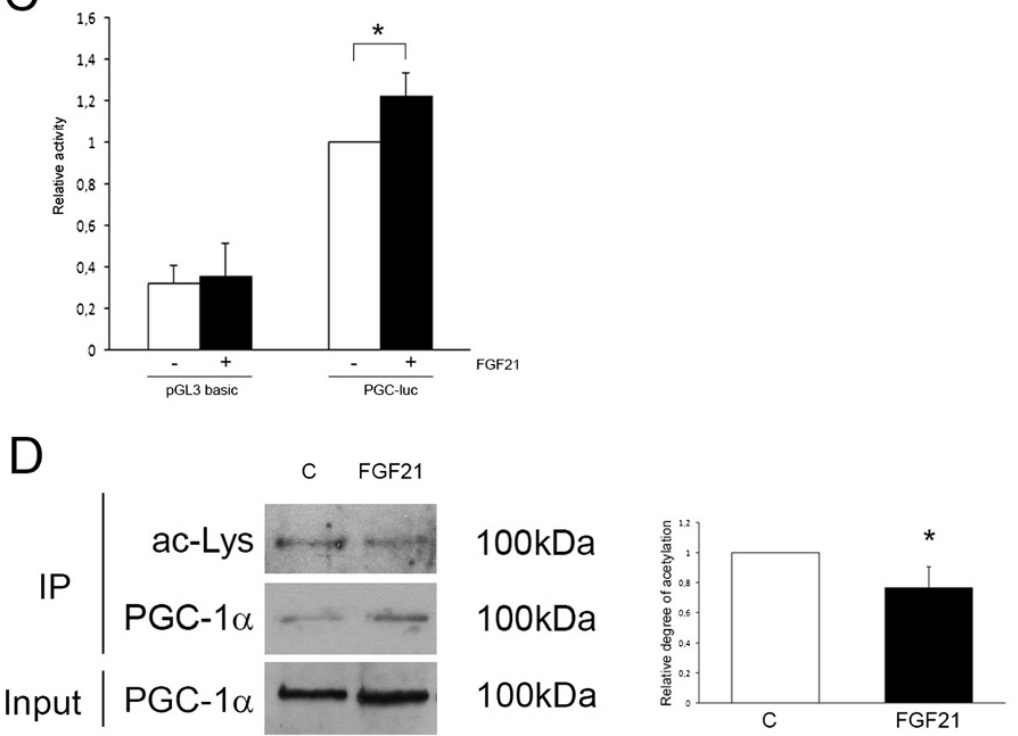

Figure 1 Effect of FGF21 on the expression and activation of PGC-1a in human dopaminergic neuron. Human dopaminergic neurons differentiated from midbrain progenitor cells were cultivated as described in Materials and methods. Cells were treated with $50 \mathrm{ng} / \mathrm{ml}$ FGF21 for $24 \mathrm{~h}$ as indicated below. (A) Left, immunoblot showing expression of tyrosine hydroxylase (TH) and dopamine transporter (DAT) in the human dopaminergic cells. $\beta$-actin was used as control. Right, phase contrast pictures. There was no significant difference in morphology between control and FGF21 treated cells. Scale bar. (B) Left, immunoblot. $\beta$-actin was used as control. The levels of PGC-1a were increased by FGF21. Right, quantification was done using ImageJ software. Values are means $\pm S D, n=4$, *** $p<0.001$ for FGF21 vs C. (C) Gene promoter assays. Cells were transfected with the PGL3 basic plasmid and the PGC-1a promoter plasmids linked to a luciferase reporter. Cells were stimulated with FGF21 for $24 \mathrm{~h}$ and the luciferase activity was measured and corrected for that of Renilla as described as described in Methods. FGF21 enhanced PGC-1a gene activity but not that of the control pGL3 promoter. Values are means $\pm S D, n=4,{ }^{*} p<0.05$ for FGF21 vs controls. (D) Immunoprecipitation experiments. PGC-1 a was immunoprecipitated from control and FGF21-treated cells followed by immunoblotting as described in Methods. The degree of acetylation of PGC-1a was analyzed using the anti-acetylated lysine antibody. Total amount of PGC-1a in the immunoprecipitate was analyzed using anti- PGC-1a antibodies. Values are means $\pm S D, n=4,{ }^{*} p<0.05$ for FGF21 vs C.

cell resistance towards oxidative stress in human dopaminergic neurons. We were also interested to investigate whether the number and biogenesis of mitochondria could be altered by FGF21 in the cultured human dopaminergic cells. To clarify this we first analyzed the levels of TFAM and of COX IV as markers for mitochondria. Data showed that neither of these proteins was increased by a $24 \mathrm{~h}$-FGF21 treatment of dopaminergic neurons compared with controls (Figure 4C). Estimation of the mtDNA content using qPCR revealed also no change in the ratio of mtDNA to nuclear DNA after FGF21 stimulations indicating an equal number of organelles in control and FGF21-treated dopaminergic neurons (Figure 4D). To substantiate this we also studied the morphology of mitochondria using electron microscopy (EM) (see Methods). Measurements of the relative mitochondrial area from 
A

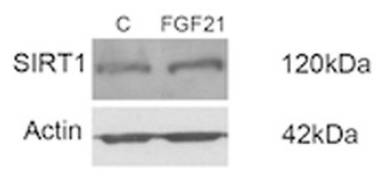

B

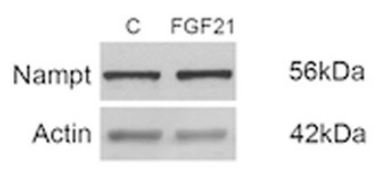

C

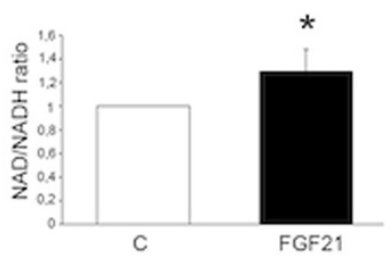

D

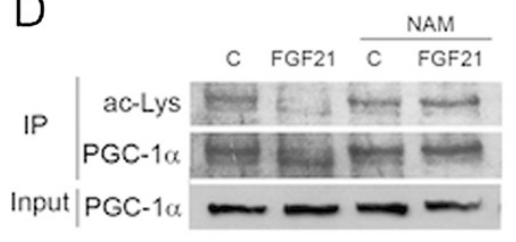

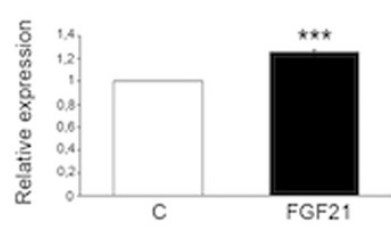

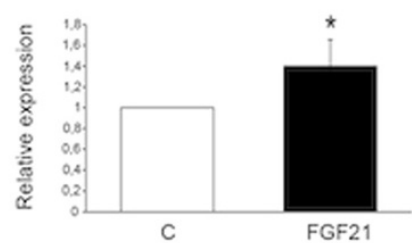

$100 \mathrm{kDa}$

$100 \mathrm{kDa}$

$100 \mathrm{kDa}$

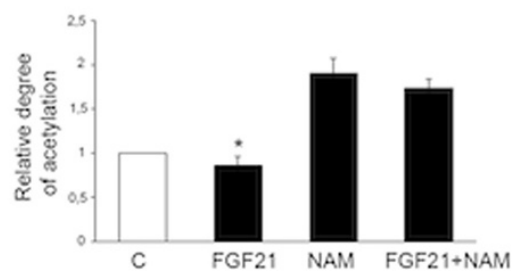

Figure 2 FGF21 increases SIRT1 and Nampt and the level of $\mathrm{NAD}^{+}$in human dopaminergic neurons. Human dopaminergic neurons were treated with $50 \mathrm{ng} / \mathrm{ml} \mathrm{FGF21} \mathrm{for} 24 \mathrm{~h}$ as indicated below. (A-B) Immunoblots. $\beta$-actin was used as a control. The levels of SIRT1 (A) and Nampt (B) were increased by FGF21. Left, immunoblots. Right, quantifications using ImageJ. Values are means $\pm S D, n=4,{ }^{* * *} p<0.001$ and ${ }^{*} p<0.05$ for FGF21-treated vs C. (C) The ratio of NAD ${ }^{+}$to NADH in the dopaminergic neurons was measured as described in Methods. FGF21 increased NAD levels in the neurons. Values are means $\pm S D, n=4,{ }^{*} p<0.05$ for FGF21 vs C. (D) Immunoprecipitation experiments. Cells were stimulated with FGF21 for $24 \mathrm{~h}$ in the absence or presence of 20 MM NAM to inhibit SIRT1. The degree of acetylation of PGC-1a was analyzed as above. Left, immunoblot. Right, quantification. FGF21 decreased PGC-1a acetylation in control cells but not in NAM treated cells. There was also an increase in acetylated PGC-1a due to SIRT1 inhibition as compared with controls. Values are means $\pm S D, n=4,{ }^{*} p<0.05$ for FGF21 vs C.

EM sections showed no significant change between control and FGF21-treated cells (Figure 4E-F). Taken together these results show that FGF21 can increase the efficacy of the mitochondria but that this is not related to an increased mitochondria number in the dopaminergic cells after treatment with FGF21.

\section{FGF21 is expressed in the midbrain and by glia cells in culture}

To study whether FGF21 is present in brain tissue, we performed immunoblotting experiment using samples from adult rodent brain and antibodies against FGF21. Data showed that FGF21 is present in different brain regions including substantia nigra and striatum that contain the cell bodies and the terminals of the midbrain dopaminergic neurons respectively (Figure 5A). Studies in vitro showed that primary glial cultures obtained from neonatal rat brain expressed FGF21 as shown by immunoblotting (Figure 5B). The relative levels of FGF21 expressed by these cells correspond to those found in the human hepatocyte Huh7 cell line (Figure 5B). This data suggest that glial cells can produce FGF21 as studied in vitro. Immunohistochemical analyses employing the anti-FGF21 antibody were not conclusive, and the precise localization of FGF21 in different brain cells will require more studies in the future.

\section{Discussion}

FGF21 is a growth factor that has been studied mainly for its effects on metabolism and cell responses in peripheral cells. The present work demonstrates that FGF21 can increase both the mitochondrial respiratory capacity and PGC- $1 \alpha$ in human dopaminergic neurons. These two effects of FGF21 in the human dopaminergic neurons are probably interconnected and related to the activation of PGC- $1 \alpha$ by this growth factor. PGC- $1 \alpha$ is known to be a major regulator of mitochondria biogenesis and functions via regulation of gene expression (Houten and Auwerx 2004; Lin et al. 2005). PGC-1 $\alpha$ also takes part in protection 


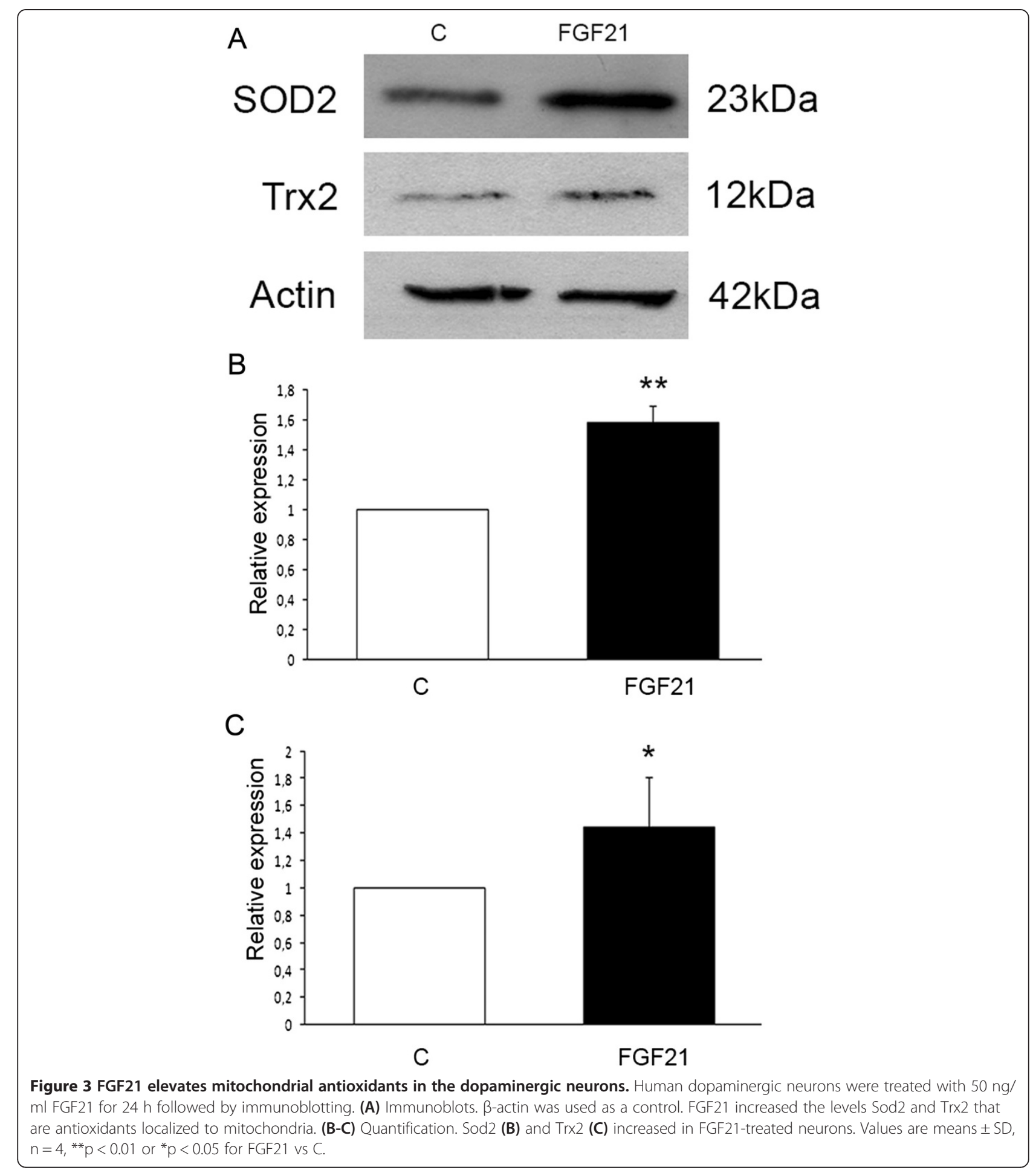

against cell stress and oxidative damage accompanying human metabolic disorders and degenerative diseases (StPierre et al. 2006). In line with this we found that FGF21 increased the levels of the antioxidant enzymes SOD2 and Trx2 localized to mitochondria in the human dopaminergic neurons. Previous studies using transgenic mice overexpressing PGC-1 $\alpha$ in dopaminergic neurons also showed an increase in these antioxidants in the midbrain. Furthermore, the compound resveratrol acting via the SIRT1/ PGC-1 $\alpha$ can also stimulate SOD2 and Trx2 levels both in cultured neurons and in the brain (Mudo et al. 2012; Kairisalo et al. 2011). As shown in vivo, the increase in mitochondrial antioxidants by PGC-1 $\alpha$ was accompanied by cell protection of dopaminergic neurons against the 


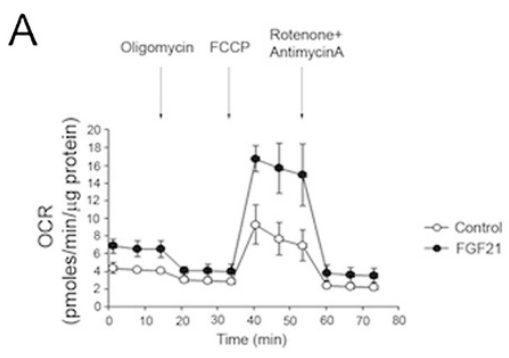

C

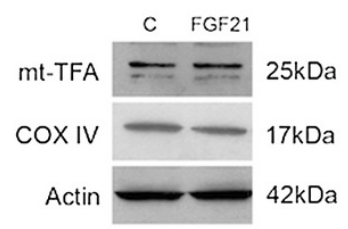

$E$

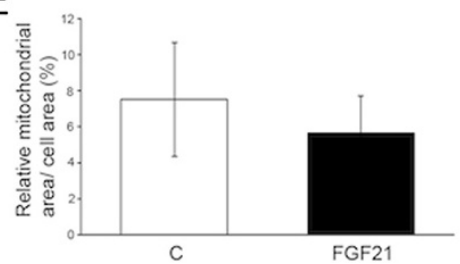

B

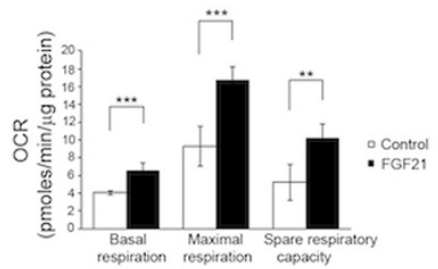

D

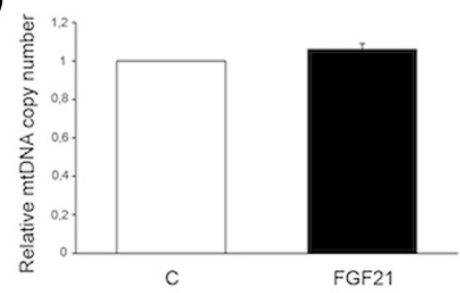

$\mathrm{F}$

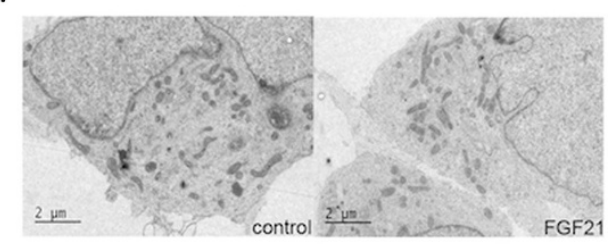

Figure 4 Effect of FGF21 on the mitochondria respiratory capacity and mitochondria number in human dopaminergic neurons. Human dopaminergic neurons were stimulated with $50 \mathrm{ng} / \mathrm{ml} \mathrm{FGF21} \mathrm{and} \mathrm{analyzed} \mathrm{further} \mathrm{as} \mathrm{indicated} \mathrm{below.} \mathrm{(A)} \mathrm{Oxygen} \mathrm{consumption} \mathrm{rate} \mathrm{(OCR)} \mathrm{in}$ human dopaminergic neurons was measured in real-time using the Seahorse equipment as described in Methods. Typical graphs after addition of the various inhibitors are shown. (B) Quantification. Basal and maximum respiration (OCR) were increase in cells treated with FGF21 as was the spare respiratory capacity. Values are means $\pm S D, n=4 .{ }^{* * *} p<0.001$ for FGF21 vs $C$. (C) Immunoblots. $\beta$-actin was used as control. The mitochondrial proteins TFAM and COX IV showed no significant changed in dopaminergic neurons treated with FGF21. (D) The mitochondrial DNA (mtDNA) copy number was analyzed using quantitative PCR as described in Methods. There was no change in the relative ratio of mtDNA to nuclear DNA reflecting an equal number of mitochondria in control and FGF21-treated dopaminergic cells. (E-F) Mitochondrial surface area. Left, control and FGF21 treated cells were analyzed by electron microscopy and the relative mitochondrial area was calculated from EM pictures as described in Methods. There were no significant changes in the mitochondrial surface area between control and FGF21 treated cells. Values are means means $\pm S D, n=4$. Right, typical EM pictures of control and FGF treated cells.

neurotoxin MPTP-induced oxidative stress (Mudo et al. 2012). Together these results show that PGC- $1 \alpha$ is an important factor in regulation of dopaminergic neuron viability and that growth factors like FGF21 may act via the induction of PGC-1 $\alpha$ and its downstream pathways in the neurons.

The mechanisms by which PGC- $1 \alpha$ are regulated have been studied in different cell types and shown to be rather complex (Houten and Auwerx 2004; Lindholm et al. 2012). Available data indicates that both transcriptional and post-transcriptional events are involved in the control of this protein. In this work we studied the mechanism by which FGF21 influences PGC-1 $\alpha$ in neurons using human dopaminergic cells as a model system (Lotharius et al. 2002; Di Liberto et al. 2012). Data showed that FGF21 increased the regulatory protein SIRT1 with the ability to de-acetylate and activate PGC- $1 \alpha$. NAD ${ }^{+}$ levels are crucial in the control of biosynthetic reactions and cell metabolism that occurs partly via SIRT1. We observed that FGF21 elevated $\mathrm{NAD}^{+}$in the dopaminergic neurons following an increase in the enzyme Nampt that is rate limiting in the biosynthesis of $\mathrm{NAD}^{+}$from NAM (Revollo et al. 2004; Yang et al. 2006). These results show that FGF21 can affect SIRT1 activity via an increase in the Nampt/NAD levels in the dopaminergic neurons. Previous studies have shown that the expression of Nampt also called pre-B-cell colony-enhancing factor (PBEF) or visfatin can be induced by nutrient restriction and by cytokines (Yang et al. 2006; Wang et al. 2006). These studies have been concerned mainly with fibroblast, vascular smooth cells or with pancreatic $\beta$ cells. In this work we show that the Nampt-SIRT1 pathway is also active in neurons and can be regulated by FGF21 signaling. These results in dopaminergic neurons add to previous data showing an involvement of Nampt in the regulation of metabolic responses, inflammation, and cell differentiation in peripheral cells (Garten et al. 2009). Given its role in the activation of 


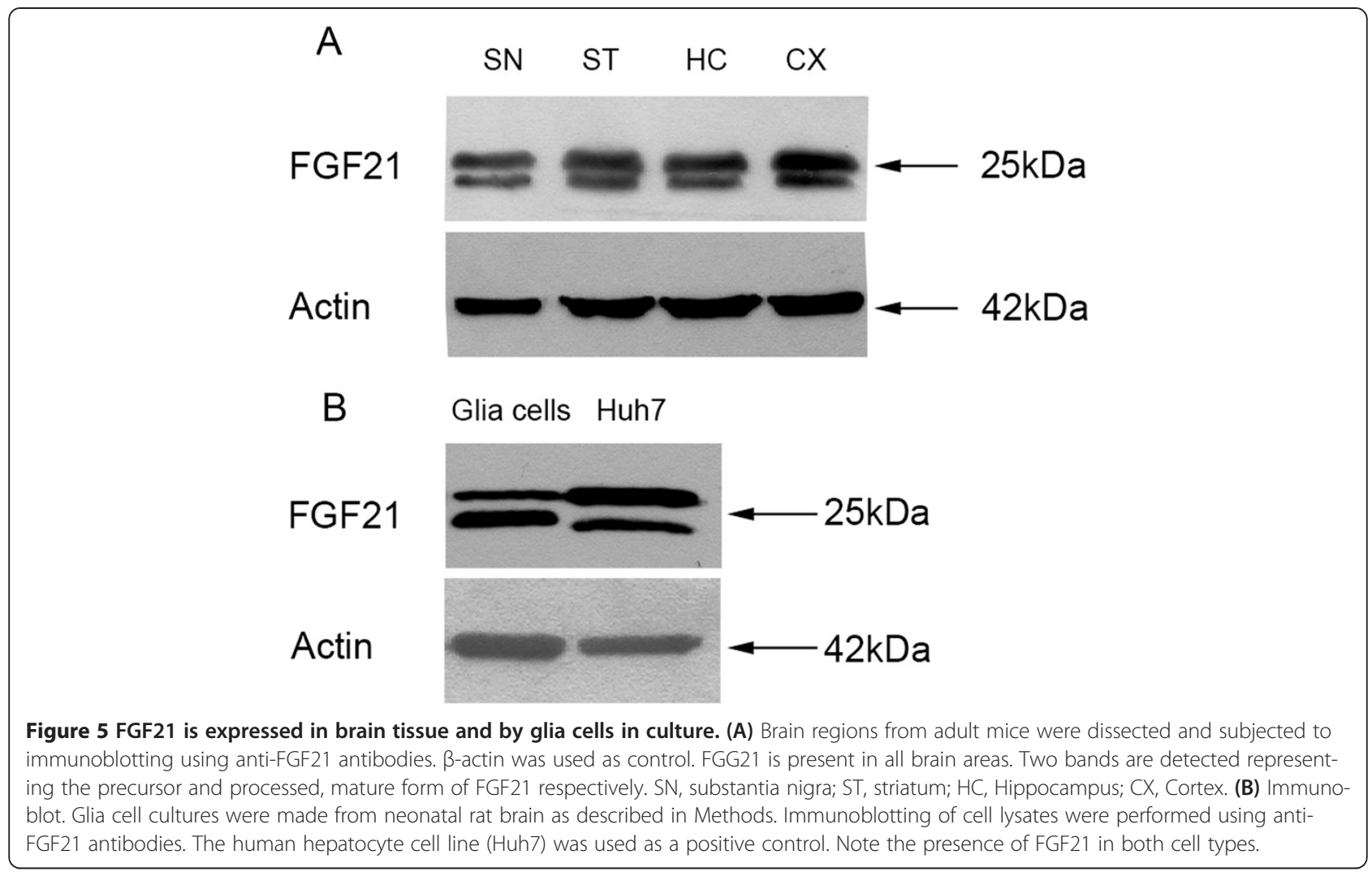

SIRT1 in dopaminergic neurons it would be interesting to study the regulation of Nampt in animal models of PD and after treatment with other factors.

To prove the point that FGF21 can stimulate mitochondrial functions in the dopaminergic neurons we performed a real-time analysis of the cells using the Seahorse equipment. Data showed that FGF21 is able to increase the mitochondrial respiratory capacity of the human dopaminergic neurons. Though not formally proven, we suspect that this effect is due to the activation of PGC$1 \alpha$ by FGF2 1 in these neurons. This data made in neurons is in line with previous results on the regulation of mitochondrial functions by the SIRT1/ PGC- $1 \alpha$ in muscle cells (Gerhart-Hines et al. 2007). Furthermore, we here also analyzed whether the copy number of these organelles increased by this growth factor. For this we studied the mitochondrial DNA copy number using PCR, and the expression of TFAM a regulator of mitochondrial biogenesis proteins and COX IV as a protein of the respiratory chain. Together the results showed that there was no significant change in any of these parameters following FGF21 treatment. This suggests that the copy number is not altered by FGF21 and that the respiratory capacity is mainly increased in the dopaminergic neurons by this growth factor. A constant level of mitochondria may arise from changes in biogenesis and degradation of the organelle that balance each other. In the future it will be interesting to study whether FGF21 may also affect the dynamics of mitochondria in dopaminergic neurons.

Previous studies have shown that several members of the large fibroblast growth factor (FGF) gene family are also expressed in the central nervous system (Itoh and Ornitz 2011). The FGFs have important functions both during development and in the mature brain (Itoh and Ornitz 2011; Mudò et al. 2009; Lahti et al. 2012). So far little is known about the expression of FGF21 in the brain. Using immunoblots we show here that FGF21 is expressed in various brain regions of adult mouse to an appreciable amount. Studies on primary brain cell cultures showed that glial cells can produce FGF21 in substantial amounts at least in vitro. Immunohistochemical analyses using the FGF-21 antibodies proven hard to perform and gave ambiguous results. Further studies using other antibodies or in situ hybridization experiments are therefore required to determine which cell types specifically express FGF21 in the brain.

One of the issues not addressed in this study is the nature of the receptors mediating the effects of FGF21 on human dopaminergic neurons. There are four types of FGF receptors, and FGF21 was shown to interact with at least FGF receptors 1-3 (Suzuki et al. 2008; Kharitonenkov et al. 2008). In addition, the protein $\beta$-Klotho is required for FGF21 to exert its biological actions (Suzuki et al. 2008; 
Kharitonenkov et al. 2008) although this may not be the case for all types of cells (Tomiyama et al. 2010). Previous studies using in situ hybridization revealed an expression of Fibroblast growth factor receptor 1 (FGFR1) in substantia nigra neurons in adult rats (Belluardo et al. 1997). However fewer data are available on human neurons, and the receptors by which FGF21 stimulates human dopaminergic neurons warrant further studies in the future.

The present study showing effects of FGF21 in dopaminergic neurons may have further physiological relevance for the regulation of cell signaling events and metabolism in brain cells. It has been proposed that neurodegeneration is accompanied by changes in neuronal metabolism or dysfunctional cell signaling that may be alleviated by the use of various drugs or growth factors (Patrone et al. 2013). FGF21 is a metabolic regulator has many beneficial effects on cell metabolism and in human metabolic diseases. The expression of FGF21 can be induced by prolonged fasting (Kharitonenkov et al. 2005; Inagaki et al. 2007) and FGF21 may also penetrate into brain tissue (Hsuchou et al. 2007). It was recently also shown using transgenic mouse that FGF21 is able to increase the life span of the animals probably due to altered cell signaling cascades (Zhang et al. 2012).

In conclusion, the present study shows that dopaminergic neurons respond to FGF21 by enhancing the mitochondrial capacity and altering gene pathways regulated by PGC-1 $\alpha$ in these cells. These results suggest that FGF21 may be of value in considering neuroprotection strategies for PD. In the future it would be interesting to study the potential benefits can be afforded by FGF21 in different neurological disorders.

\begin{abstract}
Abbreviations
ANOVA: One-way analysis of variance; COX IV: Cytochrome oxidase IV; DMEM/F12: Dulbeccos modified Eagle/F12 medium; EM: Electron microscopy; FCCP: Carbonyl cyanide 4-(trifluoromethoxy)phenylhydrazone; FGF: Fibroblast growth factor gene family; FGF21: Fibroblast growth factor-21; FGFR1: Fibroblast growth factor receptor-1; mtDNA: Mitochondrial DNA; Nampt: Nicotinamide phosphoribosyltransferase; OCR: Oxygen consumption rate; PBEF: Pre-B-cell colony-enhancing factor; PD: Parkinson's disease; PGC-1 a: Peroxisome proliferator-activated receptor $\gamma$ coactivator-1 a; SIRT1: Sirtuin-1; qPCR: Quantitative-PCR.
\end{abstract}

\section{Competing interests}

The authors declare that they have no competing interests.

\section{Authors' contributions}

$\mathrm{JM}, \mathrm{TVT}, \mathrm{FM}, \mathrm{OV}$, and HTD, carried out the different experiments in this work, as well as participated in the study design and in writing of the manuscript. GM, LTK, NB and DL took part in the design of the experiments, and drafted and finalized the manuscript. All authors read and approved the final manuscript.

\section{Acknowledgements}

We thank P Brundin for the human dopaminergic cell line. Supported by Sigrid Juselius Foundation, Academy of Finland, Finska Läkaresällskapet, Liv och Hälsa, The Finnish Parkinson Foundation, Svenska Kulturfonden, Minerva
Foundation, and Progetti di Ateneo (Università di Palermo). FM was supported by an Erasmus Training Grant.

\section{Author details}

${ }^{1}$ Institute of Biomedicine/Biochemistry and Developmental Biology, University of Helsinki, Haartmaninkatu 8, FIN-00290 Helsinki, Finland. ${ }^{2}$ Minerva Foundation Institute for Medical Research, Biomedicum-2, FIN-00290 Helsinki, Finland. ${ }^{3}$ Department of Experimental Biomedicine and Clinical Neuroscience, Division of Human Physiology, University of Palermo, Corso Tukory 129, I-90134 Palermo, Italy.

Received: 11 October 2013 Accepted: 30 December 2013

Published: 2 January 2014

\section{References}

Abou-Sleiman PM, Muqit MM, Wood NW (2006) Expanding insights of mitochondrial dysfunction in Parkinson's disease. Nat Rev Neurosci 7(3):207-219

Alcaín FJ, Villalba JM (2009) Sirtuin activators. Expert Opin Ther Pat 19(4):403-414. Doi: 10.1517/13543770902762893

Banerjee R, Starkov AA, Beal MF, Thomas B (2009) Mitochondrial dysfunction in the limelight of Parkinson's disease pathogenesis. Biochim Biophys Acta 1792(7):651-663. Doi: 10.1016/j.bbadis.2008.11.007

Belluardo N, Wu G, Mudo G, Hansson AC, Pettersson R, Fuxe K (1997) Comparative localization of fibroblast growth factor receptor-1,-2, and-3 mRNAs in the rat brain: in situ hybridization analysis. J Comp Neurol 379(2):226-246. 57

Chau MD, Gao J, Yang Q, Wu Z, Gromada J (2010) Fibroblast growth factor 21 regulates energy metabolism by activating the AMPK-SIRT1-PGC-1a pathway. Proc Natl Acad Sci U S A 107(28):12553-12558. Doi: 10.1073/ pnas. 1006962107

Cui L, Jeong H, Borovecki F, Parkhurst CN, Tanese N, Krainc D (2006) Transcriptional repression of PGC-1a by mutant huntingtin leads to mitochondrial dysfunction and neurodegeneration. Cell 127(1):59-69

Di Liberto V, Mäkelä J, Korhonen L, Olivieri M, Tselykh T, Mälkiä A, Do Thi H, Belluardo N, Lindholm D, Mudò G (2012) Involvement of estrogen receptors in the resveratrol-mediated increase in dopamine transporter in human dopaminergic neurons and in striatum of female mice. Neuropharmacology 62(2):1011-1018. Doi: 10.1016/j.neuropharm.2011.10.010

Do HT, Tselykh TV, Makela J, Ho TH, Olkkonen VM, Bornhauser BC, Korhonen L, Zelcer N, Lindholm D (2012) Fibroblast growth factor-21 (FGF21) regulates low-density lipoprotein receptor (LDLR) levels in cells via the E3-ubiquitin ligase Mylip/ldol and the Canopy2 (Cnpy2)/Mylip-interacting saposin-like protein (Msap). J Biol Chem 287(16):12602-12611. Doi: 10.1074/jbc.M112.341248

Fisher FM, Kleiner S, Douris N, Fox EC, Mepani RJ, Verdeguer F, Wu J, Kharitonenkov A, Flier JS, Maratos-Flier E, Spiegelman BM (2012) FGF21 regulates PGC-1a and browning of white adipose tissues in adaptive thermogenesis. Genes Dev 26(3):271-281. Doi: 10.1101/gad.177857.11

Garten A, Petzold S, Körner A, Imai S, Kiess W (2009) Nampt: linking NAD biology, metabolism and cancer. Trends Endocrinol Metab 20(3):130-138. Doi: 10.1016/j.tem.2008.10.004

Gerhart-Hines Z, Rodgers JT, Bare O, Lerin C, Kim SH, Mostoslavsky R, Alt FW, Wu Z, Puigserver P (2007) Metabolic control of muscle mitochondrial function and fatty acid oxidation through SIRT1/PGC-1a. EMBO J 26 (7):1913-1923

Gupta A, Dawson VL, Dawson TM (2008) What causes cell death in Parkinson's disease? Ann Neurol 64(Suppl 2):S3-S15

Handschin C, Spiegelman BM (2006) Peroxisome proliferator-activated receptor $\gamma$ coactivator 1 coactivators, energy homeostasis, and metabolism. Endocr Rev 27(7):728-735

Henchcliffe C, Beal MF (2008) Mitochondrial biology and oxidative stress in Parkinson disease pathogenesis. Nat Clin Pract Neurol 4(11):600-609. Doi: $10.1038 /$ ncpneuro0924

Houten SM, Auwerx J (2004) PGC-1a: turbocharging mitochondria. Cell 119(1):5-7 Hsuchou H, Pan W, Kastin AJ (2007) The fasting polypeptide FGF21 can enter brain from blood. Peptides 28(12):2382-2386

Hyrskyluoto A, Pulli I, Törnqvist K, Ho TH, Korhonen L, Lindholm D (2013) Sigma-1 receptor agonist PRE084 is protective against mutant huntingtin-induced cell degeneration: involvement of calpastatin and the NF-KB pathway. Cell Death Dis 4:e646. Doi: 10.1038/cddis.2013.17

Inagaki T, Dutchak P, Zhao G, Ding X, Gautron L, Parameswara V, Li Y, Goetz R, Mohammadi M, Esser V, Elmquist JK, Gerard RD, Burgess SC, 
Hammer RE, Mangelsdorf DJ, Kliewer SA (2007) Endocrine regulation of the fasting response by PPARa-mediated induction of fibroblast growth factor 21. Cell Metab 5(6):415-425

Itoh N, Ornitz DM (2011) Fibroblast growth factors: from molecular evolution to roles in development, metabolism and disease. J Biochem 149(2):121-130. Doi: 10.1093/jb/mvq121

Jenner P, Olanow CW (2006) The pathogenesis of cell death in Parkinson's disease. Neurology 66(10 Suppl 4):S24-S36

Kairisalo M, Korhonen L, Sepp M, Pruunsild P, Kukkonen JP, Timmusk T, Blomgren K, Lindholm D (2009) NF-kB-dependent regulation of Brain-derived Neurotrophic factor in hippocampal neurons by X-linked Inhibitor of Apoptosis Protein. Eur J Neurosci 30(6):958-966. Doi: 10.1111/j.1460-9568.2009.06898.x

Kairisalo M, Bonomo A, Hyrskyluoto A, Mudo G, Belluardo N, Korhonen L, Lindholm D (2011) Resveratrol reduces oxidative stress and cell death and increases mitochondrial antioxidants and XIAP in PC6.3-cells. Neurosci Lett 488(3):263-266. Doi: 10.1016/j.neulet.2010.11.042

Kharitonenkov A, Shiyanova TL, Koester A, Ford AM, Micanovic R, Galbreath EJ, Sandusky GE, Hammond LJ, Moyers JS, Owens RA, Gromada J, Brozinick JT, Hawkins ED, Wroblewski VJ, Li DS, Mehrbod F, Jaskunas SR, Shanafelt AB (2005) FGF-21 as a novel metabolic regulator. J Clin Invest 115(6):1627-1630

Kharitonenkov A, Dunbar JD, Bina HA, Bright S, Moyers JS, Zhang C, Ding L, Micanovic R, Mehrbod SF, Knierman MD, Hale JE, Coskun T, Shanafelt AB (2008) FGF-21/FGF-21 receptor interaction and activation is determined by $\beta$ Klotho. J Cell Physiol 215(1):1-7

Kim D, Nguyen MD, Dobbin MM, Fischer A, Sananbenesi F, Rodgers JT, Delalle I, Baur JA, Sui G, Armour SM, Puigserver P, Sinclair DA, Tsai LH (2007) SIRT1 deacetylase protects against neurodegeneration in models for Alzheimer's disease and amyotrophic lateral sclerosis. EMBO J 26 (13):3169-3179

Kleiner S, Mepani RJ, Laznik D, Ye L, Jurczak MJ, Jornayvaz FR, Estall JL, Chatterjee Bhowmick D, Shulman Gl, Spiegelman BM (2012) Development of insulin resistance in mice lacking PGC-1a in adipose tissues. Proc Natl Acad Sci U S A 109(24):9635-9640. Doi: 10.1073/pnas.1207287109

Korhonen L, Belluardo N, Lindholm D (2001) Regulation of X-chromosome-linked inhibitor of apoptosis protein in kainic acid-induced neuronal death in the rat hippocampus. Mol Cell Neurosci 17(2):364-372

Korhonen L, Hansson I, Maugras C, Wehrle R, Kairisalo M, Borgkvist A, Jokitalo E, Sotelo G, Fisone G, Dusart I, Lindholm D (2008) Expression of XIAP in mature Purkinje cells and in retinal bipolar cells in transgenic mice induces neurodegeneration. Neuroscience 156(3):515-526. Doi: 10.1016/j. neuroscience.2008.08.005

Lagouge M, Argmann C, Gerhart-Hines Z, Meziane H, Lerin C, Daussin F, Messadeq N, Milne J, Lambert P, Elliott P, Geny B, Laakso M, Puigserver P, Auwerx J (2006) Resveratrol improves mitochondrial function and protects against metabolic disease by activating SIRT1 and PGC-1a. Cell 127 (6):1109-1122

Lahti L, Peltopuro P, Piepponen TP, Partanen J (2012) Cell-autonomous FGF signaling regulates anteroposterior patterning and neuronal differentiation in the mesodiencephalic dopaminergic progenitor domain. Development 139 (5):894-905. Doi: 10.1242/dev.071936

Lees AJ, Hardy J, Revesz T (2009) Parkinson's disease. Lancet 373(9680):20552066. Doi: 10.1016/S0140-6736(09)60492-X

Lin MT, Beal MF (2006) Mitochondrial dysfunction and oxidative stress in neurodegenerative diseases. Nature 443(7113):787-795

Lin J, Handschin C, Spiegelman BM (2005) Metabolic control through the PGC-1 family of transcription coactivators. Cell Metab 1(6):361-370

Lindholm D, Castrén E, Kiefer R, Zafra F, Thoenen H (1992) Transforming growth factor- $\beta 1$ in the rat brain: increase after injury and inhibition of astrocyte proliferation. J Cell Biol 117(2):395-400

Lindholm D, Eriksson O, Korhonen L (2004) Mitochondrial proteins in neuronal degeneration. Biochem Biophys Res Commun 321(4):753-758

Lindholm D, Eriksson O, Mäkelä J, Belluardo N, Korhonen L (2012) PGC-1a: a master gene that is hard to master. Cell Mol Life Sci 69(15):2465-2468. Doi: 10.1007/s00018-012-1043-0

Lotharius J, Barg S, Wiekop P, Lundberg C, Raymon HK, Brundin P (2002) Effect of mutant a-synuclein on dopamine homeostasis in a new human mesencephalic cell line. J Biol Chem 277(41):38884-38894

Mäkelä J, Koivuniemi R, Korhonen L, Lindholm D (2010) Interferon- $ү$ produced by microglia and the neuropeptide PACAP have opposite effects on the viability of neural progenitor cells. PLoS One 5(6):e1 1091. Doi: 10.1371/journal.pone.0011091
Mercken EM, Hu J, Krzysik-Walker S, Wei M, Li Y, McBurney MW, De Cabo R, Longo VD (2013) SIRT1 but not its increased expression is essential for lifespan extension in caloric restricted mice. Aging Cell. Doi: 10.1111/acel.1215

Mudò G, Bonomo A, Di Liberto V, Frinchi M, Fuxe K, Belluardo N (2009) The FGF2/FGFRs neurotrophic system promotes neurogenesis in the adult brain. J Neural Transm 116(8):995-1005. Doi: 10.1007/s00702-009-0207-z

Mudo G, Makela J, Di Liberto V, Tselykh TV, Olivieri M, Piepponen P, Eriksson O, Malkia A, Bonomo A, Kairisalo M, Aguirre JA, Korhonen L, Belluardo N, Lindholm D (2012) Transgenic expression and activation of PGC-1a protect dopaminergic neurons in the MPTP mouse model of Parkinson's disease. Cell Mol Life Sci 69(7):1153-1165. Doi: 10.1007/s00018-011-0850-z

Nemoto S, Fergusson MM, Finkel T (2005) SIRT1 functionally interacts with the metabolic regulator and transcriptional coactivator PGC-1a. J Biol Chem 280(16):16456-16460

Nishimura T, Nakatake Y, Konishi M, Itoh N (2000) Identification of a novel FGF, FGF-21, preferentially expressed in the liver. Biochim Biophys Acta 1492(1):203-206

Nunnari J, Suomalainen A (2012) Mitochondria: in sickness and in health. Cell 148(6):1145-1159. Doi: 10.1016/j.cell.2012.02.035

Outeiro TF, Marques O, Kazantsev A (2008) Therapeutic role of sirtuins in neurodegenerative disease. Biochim Biophys Acta 1782(6):363-369. Doi: 10.1016/j.bbadis.2008.02.010

Patrone C, Eriksson O, Lindholm D (2013) Diabetes drugs and neurological disorders: new views and therapeutic possibilities: The Lancet Diabetes \& Endocrinology. Early Online Publication. Doi: 10.1016/S2213-8587(13)70125-6

Potthoff MJ, Inagaki T, Satapati S, Ding X, He T, Goetz R, Mohammadi M, Finck BN, Mangelsdorf DJ, Kliewer SA, Burgess SC (2009) FGF21 induces PGC-1a and regulates carbohydrate and fatty acid metabolism during the adaptive starvation response. Proc Natl Acad Sci U S A 106(26):10853-10858. Doi: 10.1073/pnas.0904187106

Revollo JR, Grimm AA, Imai S (2004) The NAD biosynthesis pathway mediated by nicotinamide phosphoribosyltransferase regulates Sir2 activity in mammalian cells. J Biol Chem 279(49):50754-50763

Rodgers JT, Puigserver P (2007) Fasting-dependent glucose and lipid metabolic response through hepatic sirtuin 1. Proc Natl Acad Sci U S A 104 (31):12861-12866

Sokka AL, Putkonen N, Mudo G, Pryazhnikov E, Reijonen S, Khiroug L, Belluardo $\mathrm{N}$, Lindholm D, Korhonen L (2007) Endoplasmic reticulum stress inhibition protects against excitotoxic neuronal injury in the rat brain. J Neurosci 27 (4):901-908

St-Pierre J, Drori S, Uldry M, Silvaggi JM, Rhee J, Jager S, Handschin C, Zheng K, Lin J, Yang W, Simon DK, Bachoo R, Spiegelman BM (2006) Suppression of reactive oxygen species and neurodegeneration by the $\mathrm{PGC}-1$ transcriptional coactivators. Cell 127(2):397-408

Suzuki M, Uehara Y, Motomura-Matsuzaka K, Oki J, Koyama Y, Kimura M, Asada M, Komi-Kuramochi A, Oka S, Imamura T (2008) $\beta$-Klotho is required for fibroblast growth factor (FGF) 21 signaling through FGF receptor (FGFR) 1c and FGFR3c. Mol Endocrinol 22(4):1006-1014. Doi: 10.1210/me.2007-0313

Tomiyama K, Maeda R, Urakawa I, Yamazaki Y, Tanaka T, Ito S, Nabeshima Y, Tomita T, Odori S, Hosoda K, Nakao K, Imura A, Nabeshima Y (2010) Relevant use of Klotho in FGF19 subfamily signaling system in vivo. Proc Natl Acad Sci U S A 107(4):1666-1671. Doi: 10.1073/pnas.0913986107

Wang T, Zhang X, Bheda P, Revollo JR, Imai S, Wolberger C (2006) Structure of Nampt/PBEF/visfatin, a mammalian NAD + biosynthetic enzyme. Nat Struct Mol Biol 13(7):661-662

Wu Z, Puigserver P, Andersson U, Zhang C, Adelmant G, Mootha V, Troy A, Cinti S, Lowell B, Scarpulla RC, Spiegelman BM (1999) Mechanisms controlling mitochondrial biogenesis and respiration through the thermogenic coactivator PGC-1. Cell 98(1):115-124

Xie H, Lev D, Gong Y, Wang S, Pollock RE, Wu X, Gu J (2013) Reduced mitochondrial DNA copy number in peripheral blood leukocytes increases the risk of soft tissue sarcoma. Carcinogenesis 34(5):1039-1043. Doi: 10.1093/ carcin/bgt023

Yang H, Lavu S, Sinclair DA (2006) Nampt/PBEF/Nisfatin: a regulator of mammalian health and longevity? Exp Gerontol 41(8):718-726

Zhang Y, Xie Y, Berglund ED, Coate KC, He TT, Katafuchi T, Xiao G, Potthoff MJ, Wei W, Wan Y, Yu RT, Evans RM, Kliewer SA, Mangelsdorf DJ (2012) The starvation hormone, fibroblast growth factor-21, extends lifespan in mice. Elife 1:e00065. Doi: 10.7554/eLife.00065

Zheng B, Liao Z, Locascio JJ, Lesniak KA, Roderick SS, Watt ML, Eklund AC, Zhang-James Y, Kim PD, Hauser MA, Grunblatt E, Moran LB, Mandel SA, Riederer P, Miller RM, Federoff HJ, Wullner U, Papapetropoulos S, 
Youdim MB, Cantuti-Castelvetri I, Young AB, Vance JM, Davis RL, Hedreen JC, Adler CH, Beach TG, Graeber MB, Middleton FA, Rochet JC, Scherzer CR (2010) PGC-1a, a potential therapeutic target for early intervention in Parkinson's disease. Sci Transl Med 2(52):52ra73. doi: 10.1126/scitranslmed.3001059

Zhou C, Huang Y, Przedborski S (2008) Oxidative stress in Parkinson's disease: a mechanism of pathogenic and therapeutic significance. Ann N Y Acad Sci 1147:93-104. Doi: 10.1196/annals.1427.023

doi:10.1186/2193-1801-3-2

Cite this article as: Mäkelä et al:: Fibroblast growth factor- 21 enhances mitochondrial functions and increases the activity of PGC-1a in

human dopaminergic neurons via Sirtuin-1. SpringerPlus 2014 3:2.

Submit your manuscript to a SpringerOpen ${ }^{\circ}$ journal and benefit from:

- Convenient online submission

- Rigorous peer review

- Immediate publication on acceptance

- Open access: articles freely available online

- High visibility within the field

- Retaining the copyright to your article

Submit your next manuscript at $\gg$ springeropen.com 